\title{
AVALIAÇÃO DE UMA EXPERIÊNCIA COM O ENSINO DE HABILIDADES CLÍNICAS PARA ALUNOS DO PRIMEIRO ANO DE PSICOLOGIA
}

\author{
EVALUATION OF AN EXPERIENCE ON THE TEACHING OF \\ CLINICAL SKILLS FOR FRESHMEN OF PSYCHOLOGY
}

Cynthia Borges de MOURA

\begin{abstract}
RESUMO
O presente trabalho teve como objetivo avaliar a experiência realizada descrevendo os efeitos do Projeto proposto sobre os alunos participantes. Avaliou-se o impacto da experiência sobre a formação dos alunos e a utilidade do modelo proposto para aprendizagem de habilidades clínicas relevantes à atuação como psicólogo. Participaram desta experiência 17 alunos do primeiro ano do curso de Psicologia da Universidade Estadual de Londrina (UEL). A realização do Projeto constou de três fases: 1) Preparação e Planejamento;2) Realização e Acompanhamento; 3) Avaliação da Experiência por alunos e supervisores. Os resultados mostraram que o Projeto, tal como foi desenvolvido, teve efeitos positivos para a formação dos alunos em vários aspectos, principalmente sobre o crescimento pessoal. Como a formação profissional do psicólogo não é algo diferente de sua formação pessoal e que ambos os repertórios (pessoal e profissional) estão em estreita relação, o impacto dessa experiência sobre a visão de homem e de mundo dos alunos e as mudanças de postura e atitudes daí decorrentes pareceram ser as contribuições mais importantes desta experiência para sua formação profissional.
\end{abstract}

Palavras-chave: Formação profissional, Treino de habilidades clínicas, Relação teoria-prática.

\begin{abstract}
The present work aimed at evaluating the experience developed describing the effects of the proposed Project upon the participants, concerning the impact on their education and the use of the proposed model in the learning of relevant clinical abilities to their actuation as a psychologist. Seventeen Psychology's freshmen of Universidade Estadual de Londrina participated in the experience.
\end{abstract}


The Project was carried out in three phases: 1) Preparation and Planning; 2) Realization and Accompaniment; and 3) Evaluation of the experience by students and supervisors. The results showed that the Project, as developed, had positive effects upon the students's education, in several aspects, but mainly upon their personal growlh. Since the Psychologist's education is not different from his/her personal formation, and since both repertoires (personal and professional) are closely related, the impact of such experience on the students'vision of the world and of mankind and the change in attitudes that followed seem to be the most important contributions of the experience on the student's professional education.

Key-words: Professional Educational, Clinical Abilities, Theory-Practice Relation

Introduzir alunos dos primeiros anos do curso de Psicologia num trabalho prático que proporcionasse a eles um contato inicial com a realidade do trabalho psicológico, na verdade, sempre foi mais uma solicitação dos próprios alunos do que um esforço dos docentes em favor da formação destes. Algumas poucas tentativas neste sentido sempre são muito limitadas colocando o aluno em contato indireto com tal realidade, ouvindo palestras ou realizando entrevistas com profissionais de diversas áreas. Tal contato além de não desenvolver no aluno habilidades necessárias a sua prática profissional, muitas vezes ainda fortalece a visão idealista e estereotipada da profissão, do profissional e das áreas de atuação, não levando o aluno a considerar formas alternativas de inserção do psicólogo em novos espaços de trabalho.

Trabalhando como docente do primeiro ano, também sentia necessidade de introduzílos em tal prática, mas esbarrava com a limitação de como fornecer uma atividade prática protegida, na qual eles pudessem atuar sem ônus para a população-alvo, (dada a falta de subsídios teóricos dos mesmos), e ao mesmo tempo fornecessem uma contribuição significativa para esta população (dado que a maioria dos trabalhos iniciais do curso são observacionais). Desta forma, um trabalho comunitário de caráter preventivo pareceu ser a melhor alternativa.
Atuando como coordenadora de um Projeto de Extensão da Universidade Estadual de Londrina que vem sendo desenvolvido junto a um Projeto da Prefeitura (Projeto Piá) que atende crianças e adolescentes de uma comunidade pobre da cidade como objetivo de prevenção a delinqüência, vi neste contexto o espaço ideal para realizar este trabalho conciliando as necessidades dos alunos e da comunidade. Organizou-se assim o intitulado "Projeto de Férias" que envolvia o planejamento e a realização de uma semana intensiva de atividades recreativas dirigidas, durante as férias escolares de janeiro e julho, com os seguintes objetivos:

1) Oportunizar um espaço para que as crianças e adolescentes ligados ao Projeto Piá usufruam de atividades lúdicas e recreativas voltadas para o desenvolvimento da criatividade e socialização;

2) Fornecer aos educadores do Projeto Piá oportunidade de reciclagem de conhecimentos pela aprendizagem direta de novas estratégias de interação e uso de recursos lúdicos;

3) Proporcionar aos alunos dos primeiros anos do curso de Psicologia uma expe-riência prática no contato com a reali-dade que permitam a eles desenvolver e/ou aprimorar habilidades de interação e trabalho com crianças. 
A proposição deste Projeto foi a alternativa encontrada para que algumas dificuldades com este tipo de inserção do aluno iniciante pudessem ser superadas. O Projeto apoiou-se nas seguintes suposições:

1) Os alunos teriam um contato muito próximo com o trabalho psicológico em comunidades, uma vez que atuariam diretamente com a população, tendo a direção das atividades sob sua responsabilidade. Desta forma, não realizariam um trabalho meramente observacional e poderiam se envolver nas dificuldades concretas do trabalho prático e na realidade da comunidade atendida;

2) Os alunos realizariam um trabalho com "características psicológicas", uma vez que deveriam planejar e executar atividades recreativas direcionadas para o desenvolvimento da socialização, criatividade, cooperação e habilidades sócio-emocionais das crianças e não voltadas apenas para o entretenimento das mesmas;

3) O trabalho em si não traria riscos para a comunidade pois, dado seu enfoque preventivo, não envolveria intervenção direta sobre problemas apresentados;

4) A comunidade poderia se beneficiar com os objetivos do Projeto: crianças teriam oportunidade para treinar e desenvolver habilidades importantes de convívio social e educadores poderiam acompanhar as atividades e aprender a utilizar novos recursos para seu trabaIho cotidiano com as crianças;

5) Finalmente, caso os objetivos propostos não fossem completamente atingidos, dadas as suposições anteriores, nenhuma das partes envolvidas seria prejudicada com o desenvolvimento de uma experiência como esta.

Assim, este artigo apresenta a primeira experiência com a realização deste Projeto.
Será descrita a trajetória do grupo de alunos desde a preparação até a realização e a avaliação final da experiência, a metodologia utilizada e o acompanhamento/ supervisão durante a realização das atividades. O que sentimos, o que aprendemos, o que precisamos mudar ou aprimorar, e a contribuição deste Projeto para os objetivos e necessidades iniciais dos alunos são focos da análise crítica realizada. A utilidade deste modelo para a inserção inicial do aluno à prática e para a aprendizagem de habilidades clínicas relevantes a atuação como psicólogo serão também analisadas.

\section{Aspectos essenciais à formação de Psicólogos}

A formação do psicólogo tem sido amplamente discutida nestes últimos anos. Muita atenção tem sido dada a questão da formação do profissional da Psicologia em todos os seus aspectos. Discute-se desde os conteúdos teóricos imprescindíveis a formação (Shook, Clair, Harstsfield e Hermingway, 1995) até as habilidades específicas para o bom exercício da profissão nas diversas áreas de atuação, dando ênfase a estruturação dos currículos dos cursos e as estratégias de ensino (Rangé,Guilhardi, Kerbauy, Falcone e Ingberman,1995). Quanto a formação em Psicologia Clínica muitos relatos são encontrados em relação a definição de quais comportamentos são relevantes a um psicoterapeuta, qualquer que seja a abordagem teórica que ele assuma (Pollack e Slan, 1995).

\section{Terapia Comportamental: Que habilidades são requeridas do terapeuta?}

Falando especificamente da formação do terapeuta comportamental, Rangé, Guilhardi, Kerbauy, Falcone e Ingberman (1995) listaram e definiram alguns comportamentos terapêuticos relevantes que, segundo eles, favorecem a efetividade clínica do terapeuta. Alguns deles são: 1. Empatia, aceitação, interesse genuíno, calor humano e compreensão; 2. 
Apoio; 3. Diretividade e controle; 4.Questionamento; 5. Clarificação e estruturação; 6 . Interpretação; 7. Confrontação e crítica; 8. Análise, avaliação e formulação de casos; 9 . Uso adequado de técnicas terapêuticas; 10 . Manejo de problemas especiais; 11 . Comportamento ético; 12. Capacidade de tolerância à frustração, de persistência, paciência; 13. Capacidade de não-envolvimento pessoal, de decentramento; 14. Capacidade de demonstrar ânimo, otimismo, dinamismo, carisma e liderança; 15. Equilíbrio emocional.

Guilhardi (1988) discutindo também questões relativas a formação de terapeutas comportamentais aponta algumas contingências de desenvolvimento e manutenção do repertório do terapeuta às quais ele deve responder simultaneamente: 1 . Contingências geradas pela comunidade-cliente; 2.contingências geradas pela relação terapêutica; 3 . Contingências geradas pela interação com uma equipe; 4 . Contingências geradas pela comunidade universitária; 5 . Contingências geradas pela comunidade científica. Cada um desses conjuntos de contingências, segundo ele, ajuda o terapeuta a desenvolver-se em relação a habilidades necessárias a uma boa atuação por ampliar seu repertório através das diferentes respostas que os diferentes contextos requerem do terapeuta enquanto profissional.

Pollacke Slan (1995) oferecendo sugestões a líderes de psicoterapia de grupo, entre outras coisas, abordam a questão das habilidades requeridas de um terapeuta. Eles afirmam que um terapeuta deve não apenas conhecer a si mesmo, mas também ser ele mesmo na interação com os clientes. Para estes autores, a artificialidade é comumente percebida como desrespeito pelos clientes. Assim como na terapia individual, na terapia de grupo os terapeutas precisam ser bons ouvintes, ter habilidade para confrontar e assumir um enfoque teórico que norteie suas intervenções, devem ter habilidade de facilitar a auto-exposição do grupo e assegurar a participação de todos encorajando o compartilhar suas dificuldades no grupo e facilitando o feedback interpessoal.

\section{Habilidades requeridas dos psicoterapeutas de crianças}

Falando agora especificamente do trabaIho com crianças, alguns autores têm ressaltado que o treinamento de terapeutas que trabaIham com crianças deve ter duas características básicas: amplitude e diversificação (Stephen e Phillips, 1991 apud Conte, 1993).Os temas básicos que terapeutas deveriam dominar seriam o desenvolvimento humano (pais e crianças), tipos e severidade de problemas infantis, aspectos culturais (étnicos,sócio-econômicos), contexto de intervenção e modalidades de tratamento.

Conte (1993) abordando a questão da formação de terapeutas, concorda que terapeutas de crianças devem compartilhar as características apontadas para terapeutas de adultos, e além disso apresentar algumas habilidades específicas para o trabalho terapêutico com crianças. Esta autora relaciona alguns comportamentos e habilidades clínicas que parecem ser muito relevantes ao terapeuta de crianças:

1) Ter capacidade de permanecer relaxado, à vontade frente a criança, não se comportando como censor, pai ou professor;

2) Ter uma empatia de "mão-dupla": conseguir alternar papéis e olhar para os fatos ora do ponto de vista dos pais e ora do ponto de vista da criança (pois muitas vezes eles são contraditórios);

3) Gostar de brincar e saber brincar com a criança, ter habilidade para fazer coisas que elas gostam;

4) Transpor o brincar para o desenvolvimento dos objetivos terapêuticos;

5) Ter um amplo repertório para poder alternar propostas na direção do desejado. Não ser excessivamente preso ao programado (metódico); 
6) Ter flexibilidade e criatividade, só possível com um amplo repertório;

7) Saber lidar com perguntas de ordem pessoal, por parte da criança;

8) Ter habilidade para lidar com pressões sociais (pais, escola, etc, e com expectativas sociais versus bem estar da criança).

9) Saber esperar pelos resultados, e não ter ansiedade em mostrar serviço.

\section{Treinamento de psicoterapeutas: quais são as alternativas?}

Segundo Conte (1993), no treinamento de terapeutas, o curso de psicologia pode estar gerando regras sobre qual éa postura desejável para o terapeuta, baseadas em modelos estáti$\cos$, que não consideram aspectos ambientais e contextuais. A proposta que ela apresenta é a de que, mais do que seguir regras, o terapeuta esteja atento e se deixe modelar pelas contingências especiais de cada caso, prestando atenção a "quem dirige que tipo de procedimento, para que tipo de indivíduo ou família, com que tipo de problema, em que contexto". Segundo esta autora, o terapeuta deve se desenvolver sob controle do desenvolvimento pessoal do seus clientes e das contingências presentes na psicoterapia.

Poucos estudos apontam para como estas habilidades podem ser ensinadas. Alguns poucos trabalhos sobre supervisão, indicam alguns caminhos para o ensino de habilidades a alunos de final de curso (Silvares, 1997). Nenhum relato foi encontrado sobre trabalhos práticos de qualquer natureza envolvendo alunos do início do curso. Talvez mais que uma falha, isto indique a concepção de que a teoria precede a prática e não que ambas podem caminhar juntas e subsidiar uma a outra (Morato, 1996). Este trabalho tem esta pretensão: mostrar uma experiência que está começando, mas frutificando, com o objetivo de dar a estes alunos a oportunidade de desenvolverem-se como pessoas, treinar habilidadese começarema prepa- rarem-se para uma atuação clínica futura, mostrando que a formação clínica do psicólogo pode e deve começar desde cedo, para ser mais rica e mais completa.

\section{OBJETIVOS}

1) Avaliar a experiência realizada descrevendo os efeitos do Projeto proposto sobre os alunos participantes quanto ao impacto sobre sua formação (a avaliação dos efeitos do Projeto sobre as crianças e educadores será propositadamente excluída por não fazer parte dos objetivos desta análise);

2) Avaliar a utilidade do modelo proposto para a inserção inicial do aluno à prática e para a aprendizagem de habilidades clínicas relevantes a atuação como psicólogo.

\section{MÉTODO}

Os Alunos: Participaram desta experiência 17 alunos do primeiro ano do curso de Psicologia da Universidade Estadual de Londrina (UEL). Como o Projeto foi desenvolvido nas férias escolares de fevereiro de 1998, tais alunos já haviam concluído o primeiro ano. Por ser uma primeira experiência optou-se por um número restrito de alunos participantes para testagem da proposta. Houve assim necessidade de se realizar uma seleção, dado o alto número de interessados que se inscreveram (40 alunos). Os alunos foram selecionados mediante combinação de quatro critérios: 1) disponibilidade para participação na data prevista;2) motivo pelo qual desejava participar do Projeto;3) possuir alguma experiência anterior com crianças e; 4) desempenho nas disciplinas relativas a Psicologia no primeiro ano.

A Equipe de Supervisores: O Projeto de Extensão do qual este Projeto de Férias fez parte envolvia o trabalho de três docentes, 
todas ligadas o Departamento de Psicologia Geral e Análise do Comportamento da UEL. Durante a realização do Projeto de Férias, as docentes se revezaram no acompanhamento aos alunos de modo que durante toda a semana e em cada período do dia havia uma docente no local do trabalho supervisionando as atividades e auxiliando no desenvolvimento das mesmas. No período de preparação que antecedeu a semana de atividades, as três docentes realizaram juntas o treinamento dos estagiários.

Procedimento: A realização do Projeto como um todo constou de três fases:

1) Preparação e Planejamento: Imediatamente após a divulgação dos alunos selecionados foi marcada uma reunião para explicitação das diretrizes do Projeto. Esta reunião foi realizada no final do ano letivo de 1997. Neste encontro definiu-se quais seriam as atividades, $\mathrm{e}$ - grupo concordou que seria mais adequado os seguintes agrupamentos: Música e Dança; Teatro; Argila e Sucata; e Recreação ao Ar Livre. Os alunos distribuíram-se nos quatro grupos conforme as afinidades com as atividades. Foi solicitado então que dentro destas grandes áreas eles planejassem as atividades conforme os objetivos já citados e trouxessem o planejamento para discussão nos dias marcados para preparação no próximo ano. Três dias antes da semana prevista para a realização das atividades com as crianças (em fevereiro de 1998) o grupo de alunos e de supervisores reuniu-se para verificação e adequação do planejamento, preparação de material, discussão teórica sobre o contexto de pobreza e trabalhos preventivos e visita ao local da realização do Projeto.

2) Realização e Acompanhamento: $\mathrm{Na}$ semana marcada os alunos iniciaram as atividades. Eles também montaram um revezamento de forma que uma equipe atuava pela manhã e outra a tarde desenvolvendo as mesmas atividades, uma vez que as crianças não eram as mesmas nos dois períodos. As supervisoras sempre estavam por perto acompanhando as atividades, auxiliando na sua condução, dirimindo dúvidas, resolvendo problemas. Nos intervalos das atividades, normalmente antes de começarem, às vezes ao final do dia, o grupo se reunia para conversar. Normalmente a conversa era em torno do que fazer diante dos problemas e dificuldades encontradas, tais como brigas, xingamentos, agitação, crianças que não obedeciam ordens e se dispersavam, crianças retraídas, tímidas e que não se envolviam com as atividades e com o grupo. Os supervisores ouviam a questão e qual tentativa foi feita para resolvê-la, pedia a opinião dos outros alunos a respeito da situação, e conduzia uma análise da melhor solução para aquele problema, caso ocorresse novamente.

3) Avaliação da Experiência: A avaliação do Projeto, do alcance de seus objetivos e de seu funcionamento como um todo foi realizada de duas formas: Num primeiro momento, foi solicitado aos alunos, ao final da semana, que respondessem a um formulário de avaliação. Esta avaliação formal visava promover reflexão específica sobre alguns pontos considerados relevantes para a formação dos alunos, avaliação da proposta do Projeto e reformulação de sua execução. Visava também proporcionar um espaço para a expressão de idéias, opiniões e vivências dos alunos em relação a experiência. Num segundo momento, as supervisoras realizaram a sua avaliação da semana, discutindo o que consideraram aspectos positivos e negativos, o que deveria ser mantido, reformulado e/ou implemen- 
tado numa próxima experiência. A análise dos formulários e a avaliação a posteriori do processo é realizada a seguir.

\section{RESULTADOS}

\section{Avaliação da experiência pelos alunos}

A avaliação que os alunos realizaram dessa experiência foi moldada dentro de alguns parâmetros relativamente amplos que se considerava importante para reflexão. Apesar de ter sido uma avaliação dirigida, muitas das vivências pessoais dos alunos puderam ser resgatadas em sua riqueza e originalidade. $\mathrm{Na}$ avaliação realizada foram solicitados a análise dos seguintes temas: 1) aspectos da experiência que foram positivos e úteis para você como pessoa e para a formação acadêmico-profissional; 2) aspectos positivos e aspectos a serem aprimorados no desempenho frente a organização e realização das atividades e no manejo com as criancas: 3) principais dificuldades enfrentadas quanto a conduzir atividades, interagir com as crianças, lidar com imprevistos e problemas, orientar o desenvolvimento das atividades e o comportamento das crianças para o alcance dos objetivos propostos, etc; 4) relação teóricoprática proporcionada pela experiência dentro dos limites do conhecimento já adquirido em Análise do Comportamento; 5) espaço para críticas, sugestões, idéias, recadinhos ou qualquer outra observação.

Retiramos deste material os aspectos e vivências apontados por eles como mais marcantes e significativos quanto a cada um dos aspectos solicitados. Observou-se que, mesmo tendo um parâmetro pré-delimitado, cada aluno colocou sua experiência individual e sub-temas emergiram em cada tema solicitado. Cada ítem será apresentado seguido de recortes ilustrativos dos relatos dos próprios alunos quanto a sua percepção acerca da questão.

Na tabela abaixo encontra-se um resumo dos temas principais abordados pelos alunos e dos sub-temas que emergiram dos relatos:

TABELA 1: Temas e Sub-temas emergidos da avaliação formal dos alunos

\begin{tabular}{|c|c|c|}
\hline $\begin{array}{l}\text { Tema 1: } \\
\text { Aspectos da experiên- } \\
\text { cia que foram positi- } \\
\text { vos e úteis para você } \\
\text { como pessoa e para a } \\
\text { formação acadêmico- } \\
\text { profissional }\end{array}$ & $\begin{array}{l}\text { Sub-tema 1.1: } \\
\text { Experiência relevante para vida pes- } \\
\text { soal: impacto da diferença sócio-cultu- } \\
\text { ral sobre a vida pessoal provocando } \\
\text { mudança de percepçăo, atitudes e va- } \\
\text { lores; experiência contribuiu para o } \\
\text { crescimento e para maior valorização } \\
\text { do eu e do outro. }\end{array}$ & $\begin{array}{l}\text { Sub-tema 1.2: } \\
\text { Importância para a vida profissional: } \\
\text { aprendizagem ocorrida será útil futura- } \\
\text { mente. Nẫo há identificação do para } \\
\text { quê ou em quê. Identificaram o trabalho } \\
\text { preventivo como opção de atuação pro- } \\
\text { fissional que eles conheceram mais de } \\
\text { perto. }\end{array}$ \\
\hline $\begin{array}{l}\text { Tema 2: } \\
\text { Aspectos positivos e } \\
\text { a serem aprimorados } \\
\text { no desempenho fren- } \\
\text { te a organizaçáo e } \\
\text { realização das ativi- } \\
\text { dades e no manejo } \\
\text { com as crianças }\end{array}$ & $\begin{array}{l}\text { Sub-tema 2.1. } \\
\text { Aspectos positivos: Alta motivação para } \\
\text { participar do trabalho, a boa vontade, a } \\
\text { disposição, a socializaçăo, a vontade } \\
\text { de fazer tudo certo e de ensinar e apren- } \\
\text { der. }\end{array}$ & $\begin{array}{l}\text { Sub-tema 2.2: } \\
\text { Aspectos a serem aprimorados: lidar } \\
\text { consigo mesmo frente às peculiarida- } \\
\text { des das crianças e do contexto, medo } \\
\text { de errar, falta de auto-confiança e auto- } \\
\text { controle, lidar com imprevistos, e com } \\
\text { sentimentos gerados pela situação, as- } \\
\text { sumir o domínio da situação e colocar } \\
\text { limites aos excessos das crianças. }\end{array}$ \\
\hline
\end{tabular}

